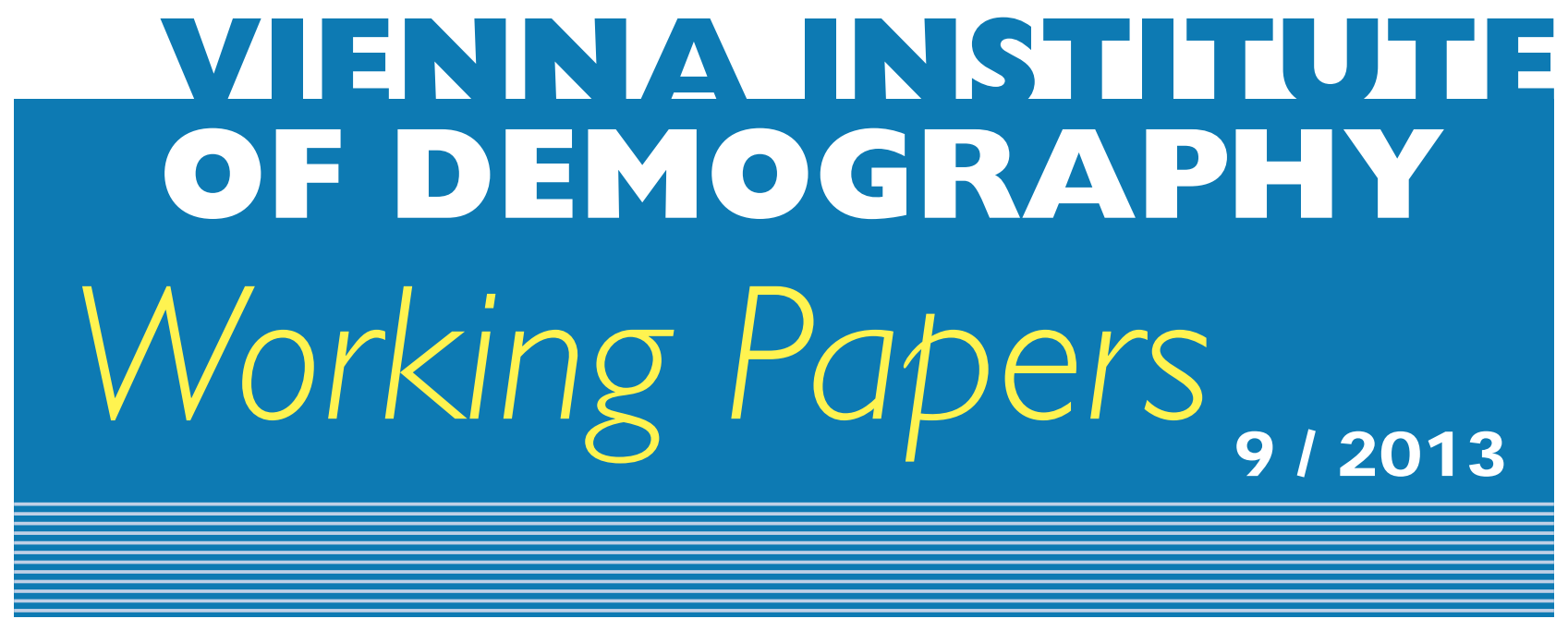

Alessandra De Rose and Maria Rita Testa

\title{
Climate Change and Reproductive Intentions in Europe
}

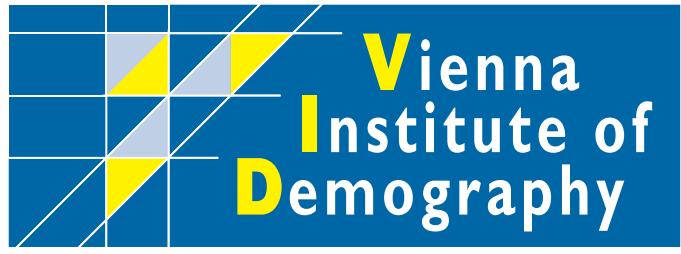

Vienna Institute of Demography Austrian Academy of Sciences

Wohllebengasse 12-14

A-1040 Vienna $\cdot$ Austria

E-Mail:vid@oeaw.ac.at

Website: www.oeaw.ac.at/vid 


\begin{abstract}
Aim of this paper is to investigate the effects of environmental conditions on human reproductive behavior in the highest industrialized countries. We discuss the hypothesis that individuals fearing for a foreseen unhealthy environment tend to delay or forgo childbearing, thus contributing to a reduced ecological footprint. The empirical analysis is based on the Eurobarometer survey carried out in the 27 EU countries in 2011. Multilevel ordinal regression models on additionally intended number of children are used. A random intercept is considered to take into account the clustering of individuals within countries. Results indicate that people's intended number of children is not very strongly correlated with people's concerns about climate change, but if a statistically significant relation is detected, this is positive: the stronger the concern, the higher the intended number of children. This result suggests that the desire to pass an enjoyable and healthy environment to the future generations does not refrain people to plan large families and that the parents' environmental concern can be instrumental in stimulating parents' responsible behaviours and proper policies at institutional level.
\end{abstract}

\title{
Keywords
}

Climate change, fertility intentions, environmental conditions, fertility, multi-level analysis, Europe

\section{Authors}

Alessandra De Rose is Professor at Sapienza University of Rome. Department of Methods and Model for Economics, Territory and Finance. Email: alessandra.derose@uniroma1.it

Maria Rita Testa is Senior Research Scholar at the Wittgenstein Centre (IIASA, VID/OEAW, WU), Vienna Institute of Demography of the Austrian Academy of Sciences. Email: Maria.Rita.Testa@oeaw.ac.at

\section{Acknowledgements}

This study has been conducted in the framework of the project "Population Dynamics and Climate Changes: Micro and Macro Analysis of Reciprocal Influences" granted to Alessandra De Rose by Sapienza University of Rome. A previous version of this work has been presented at the Conference in honour of Giuseppe Burgio organized by the European Association of Development Research and Training Institutes and EUROSAPIENZA (Research Centre for European, International and Development Studies), held in Rome on 6 November 2013. We would like to thank the participants to this Conference for their valuable comments. Any shortcomings are the responsibility of the authors. 


\title{
Climate Change and Reproductive Intentions in Europe
}

\author{
Alessandra De Rose and Maria Rita Testa
}

\section{Introduction}

The harsh impacts of climate change and related hazards are increasingly being felt across the world. A large consensus has emerged among natural scientists about the nature and the impact of climate change. It is widely recognized that climate change is largely anthropogenic and that, in turn, a continuous worsening of environmental conditions has a strong impacts on populations' and individuals’ well-being (Lutz 2010).

Besides the direct negative effect on mortality and morbidity caused by extreme events, such as: severe storms, hurricanes, inundations, etc., climate change, and more generally, the worsening of environmental conditions threatens traditional livelihoods. People will be exposed to increasing health hazards, or they can be forced to leave their home (Piguet 2008), or change their family living arrangement (Rendall 2011).

Whether and to what extent these hazards will result in human fatalities depends on the vulnerability of the people affected, meaning their robustness and resilience, which are in turn affected by socio-economic development level of the population involved (McBean and Ajibade 2009). This should result in the adoption of different strategies for strengthening adaptive capacities to cope with unavoidable climate change (Lutz 2010).

In countries where environmental sensitivity is increasing, people may respond to climate change also by adopting more responsible behaviors and attitudes.

The aim of this paper is to investigate the effects of the worsening environmental conditions on human reproduction intentions in the European countries. Firstly, we present a theoretical framework for the relation between environmental sensitivity and human choice; then, we test the hypothesis that the more sensitive individuals and those fearing for a foreseen unhealthy environment may adopt attitudes and behaviors leading to a delayed or a foregone childbearing, thus contributing to a reduced ecological footprint.

\section{Background: Climate Change and Human Choices}

An important question to be answered is whether and how people contribute to moderate the environmental risks or react to them by making informed or wise choices. Humans can choose to respond to the prospect of climate change and can decide, with certain degrees of freedom, what steps to take. At community level, they can develop new technologies that will allow economic development while reducing the anthropogenic contributions to climate change. Since it is a global issue, the most influential decision makers are the Governments, which define goals (such as emissions reductions) and adopt specific policy 
instruments (e.g., a carbon tax). This is the reason why most of the social sciences research on the topic of climate change focuses on the macro level of national and international political choices. However, research at the macro level may reduce important dimensions of actions and decisions taken at different levels, closer to the individuals. The slogan, "Think globally_act locally" expresses the widespread recognition that choices are made at the micro level, by individuals and groups in particular places. Even in the context of national or international regulations, firms, families, communities, and citizens choose how to respond to incentives and sanctions, or to try independent and voluntary strategies to moderate or adapt to environmental issues, by means of responsible behaviors (Rayner and Malone 1998).

The voluntary childbearing limitation - strongly advocated by international institutions (O’Neill 2002) - can be considered as a responsible behavior that individuals should adopt both to reduce the ecological footprint and to avoid exposing a new pregnancy and the unborn child to environmental risks.

The relationship between environmental concerns and fertility is an issue that has not received a great deal of attention in the literature (Swim et al. 2009). Some recent studies have demonstrated a link between local environmental concerns and reduced fertility. For instance Ghimire and Mohai (2006) examined the relationship between three specific environmental concerns (agricultural productivity, water quality, and status of groundwater table) and contraceptive use in the Chitwan Valley in Nepal, and they found that concern over crop production was positively associated with contraceptive use, after controlling for a set of relevant demographic variables. They argued that the impact of increasing environmental concerns on fertility behavior may be more prevalent in societies where locally used resources are scarce.

Also, there has been only little empirical investigation on the relationship between environmental concerns and fertility intentions. An important exception is the study carried out in the Thunder Bay (Canada) by Arnocky et al. (2012). This research has shown that couples who believe that pollution has affected their physical and mental health tend to have a less positive attitude toward having children and desire to have fewer children in their lifetime than people not concerned about the negative impact of pollution on their health status (Arnocky et al. 2012).

Here we explore the hypothesis that in European countries the spread of environmental awareness and the fear of the effects of climate change are increasingly popular as reasons not to have children or to delay its calendar.

\section{Research Hypotheses}

There are two main types of environmental concerns that can be considered in a study of fertility intentions: the first one involves concerns about humanity's role in affecting natural environment; the second one considers concerns with human beings' health risks due to pollution. In relation with fertility intentions these concerns can be translated as follows: individuals who believe they can make a positive contribution to the environment 
may tend to remain childless; alternatively, they may believe that poor environmental quality may threaten the well-being of potential offspring. Of course, fertility intentions are determined by a set of different individual- and contextual-level factors and it is difficult to disentangle the impact of subjective environmental concerns from the influence of all these other factors at both individual and contextual level.

In this study, we suppose that individuals' fertility intentions are negatively influenced by their environmental concerns (research hypothesis 1) and that this relationships holds not only at individual but also at country level across the EU countries (research hypothesis 2); moreover, the negative climate change - intention relation is significantly moderated by educational level: people who are better educated and do have concerns on climate change tend to indicate a preference for smaller family sizes than their less educated and worried counterpart (research hypothesis 3 ). The more educated people may think that the environmental challenge can be faced successfully with some progress and responsible behaviors.

\section{Data}

The empirical analysis is based on the Eurobarometer surveys (EB) carried out in 2011 in the $27 \mathrm{EU}$ countries. In this survey the stratified sampling procedure assures nearly equal probability samples of about 1,000 respondents in each of the countries. The sample size allows equally precise estimates for small and large countries, as well as to make comparisons between sub-groups broken down by sex, age, education, marital status, and so on. The surveys used a single uniform questionnaire design, with particular attention being paid to equivalent question wording across languages.

The analytical sample consists of 8,278 people aged 20 to 45 who answered the question on fertility intentions as well as the question on concerns about climate change. The non-response rate was slightly less than $10 \%$. A missing answer may be symptomatic of certain fertility plans (Morgan 1981 and 1982). However, we simply excluded from the analysis all individuals who did not report any intended family size in order to avoid potential complications given the absence of auxiliary information on this item. The results obtained from the analysis run on the sub-set of valid responses are reliable under the standard "missing at random assumption" (Little and Rubin 2002).

The models are formally based on two levels: individuals and countries (referred to as "clusters") as described in Table 1. As is shown in this table, the hierarchical structure is quite unbalanced. This lack of balance is not a problem, as it is efficiently handled by maximum-likelihood methods. The number of clusters and their sizes are sufficient to achieve high levels of power and accuracy of the asymptotic distributions of the estimators (Stegmueller 2013; Snijders and Bosker 1999), and thus allow for reliable inferences. Multilevel models assume random sampling at all levels, while our survey design in fact does not use sampling at the country level. Even in this latter case the use of multilevel models is justified on the basis of the advantages offered by this approach, i.e., explicit inclusion of country-level explanatory variables and country-level residual variation in the models (Hox et al.2012). 
For the estimates computation we used the program gllamm which runs in the statistical package Stata and estimates GLAMMs (Generalized Linear Latent and Mixed Models) by maximum likelihood, i.e., via a maximization algorithm with adaptive quadrature, assuming Gaussian random effects (Skrondal and Rabe-Hesketh, 2004).

Table 1: Structure of the data: respondents aged 20 to 45 by country. EB 2011

\begin{tabular}{|c|c|c|c|}
\hline & PARITY 0 & PARITY 1 & PARITY 2 \\
\hline Austria & 174 & 75 & 103 \\
\hline Belgium & 149 & 71 & 112 \\
\hline Bulgaria & 104 & 107 & 118 \\
\hline Cyprus & 98 & 24 & 49 \\
\hline Czech republic & 145 & 101 & 162 \\
\hline Denmark & 122 & 57 & 93 \\
\hline Estonia & 115 & 95 & 110 \\
\hline Finland & 91 & 44 & 74 \\
\hline France & 123 & 76 & 111 \\
\hline Germany & 227 & 102 & 110 \\
\hline Greece & 209 & 68 & 92 \\
\hline Hungary & 130 & 95 & 119 \\
\hline Ireland & 96 & 73 & 86 \\
\hline Italy & 169 & 83 & 99 \\
\hline Latvia & 151 & 147 & 122 \\
\hline Lithuania & 141 & 82 & 109 \\
\hline Luxembourg & 72 & 43 & 52 \\
\hline Malta & 48 & 33 & 47 \\
\hline Netherlands & 164 & 41 & 86 \\
\hline Poland & 95 & 67 & 70 \\
\hline Portugal & 119 & 99 & 94 \\
\hline Romania & 135 & 126 & 98 \\
\hline Slovakia & 125 & 89 & 135 \\
\hline Slovenia & 137 & 67 & 84 \\
\hline Spain & 177 & 86 & 118 \\
\hline Sweden & 85 & 49 & 56 \\
\hline United Kingdom & 155 & 96 & 117 \\
\hline TOTAL & 3556 & 2096 & 2626 \\
\hline
\end{tabular}




\section{Model}

Multilevel models were run in order to represent the complex causal process underlying the behaviour of individuals living in a social context, and to draw valid inferences regarding the relationships at the relevant hierarchical levels. As is usual in a multilevel setting, the clustering of individuals in countries is a phenomenon of interest, rather than a mere disturbance (Snijders and Bosker 1999).

In Figure 1, freely inspired by Coleman (1990), the multilevel framework is adapted to the study of individual's lifetime reproductive intentions. The box visible at the top right of the scheme is related to fertility rates, which are not investigated in the current analysis, but depend on the relationship explicitly considered in the current study. A crucial characteristic of the multilevel setting is that the effect of the context on the individual outcome can be estimated after a control for the individual-level characteristics is included in the model (the diagonal line in the scheme).

The multilevel analysis relies on the random intercept version of the proportional odds model for ordinal responses (e.g., Agresti, 2002). All of the models were run separately by parity: zero, one, and two children. As was stated in the rational choice theories approach (Yamaguchi and Ferguson 1995), fertility intentions may change after each new birth, in line with the concept of a conditional-sequential fertility decisionmaking process (Namboodiri 1972). The preference for models stratified by parity over pooled models with parity interactions is reinforced by reasons of parsimony. A problem arises when there is selection in a parity-specific analysis; i.e., there are unobservable variables that could be correlated with the probability of having a child in parity n, as well as with the probability of intending to have a child of the next order, $n+1$. The consequence is a biased and inconsistent estimator. This problem is not tackled here because of a lack of adequate longitudinal retrospective information, but the related issue is discussed in the concluding section.

The proportional odds model could be extended to handle partial proportional odds (Williams 2006), but then the interpretation becomes somewhat tortuous. Since only a few covariates in each model violated such an assumption, and since they did so only slightly, the proportional odds multilevel models were preferred.

Figure 1: A micro-macro model of fertility, freely inspired by Coleman 1990

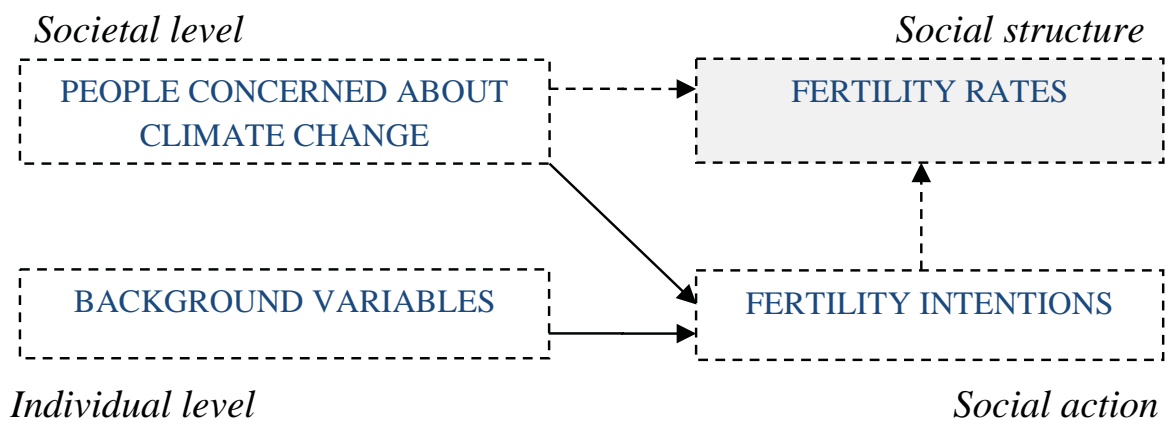




\subsection{Response Variable: Lifetime Fertility Intentions}

The response variable, i.e., the intended number of children, was measured through the following item: "How many more children do you intend to have?" A range from zero to up to six children was given in the questionnaire as a response option. The prospective item was asked immediately after the question about the number of children already had ("How many children, if any, have you had?") and was clearly intended to provide information about the number of births respondents plan to have over (the rest of) their reproductive careers. Neither of the above-mentioned questions made a distinction between biological and adopted children. Moreover, since pregnancies are not measured in the survey, it cannot be excluded that pregnant women reported the children already conceived at the time of the survey as expected to be born, i.e., in the intended component of their ultimately intended family size. A descriptive analysis of lifetime reproductive intentions as measured in the 2011 Eurobarometer survey can be found in Testa 2012.

The response variable was coded as a four-category variable: zero, one, two, and three or more children. Values greater than or equal to three were, in light of their low frequency, collapsed into a single category.

\subsection{Concerns about Climate Change and other Explanatory Variables}

Our key covariate refers to the people's concern about climate change. Respondents were asked to report whether they consider climate change as either one of the biggest problem for the future, or the biggest problem for the future. $50 \%$ of the respondents reported climate change as one of the future problems and $20 \%$ of the respondents indicated it as the biggest one. No missing answers or refusals were registered for these two survey questions. A dummy variable indicating whether people worry that climate change will be the biggest problem for the future has been entered in the models. As can be seen in Table 2 , there are no differences by parity in the share of people who are concerned.

The explanatory variables of the models are as follows: age, sex, enrolment in education, level of education, marital status, employment status, and self-location on the social scale. All of the covariates refer to the time of the interview. Unfortunately, the data do not carry any retrospective information concerning the previous history of respondents, which would have allowed me to estimate the role of biographical trajectories on the process of forming family size intentions in a dynamic framework. The assumption of constancy over time is quite reasonable for some covariates, like, for instance, completed educational level; for the other covariates, I simply assume that they exert an influence as they are measured at the time of the survey, independently on whether the different statuses (marital, employment, social) have been reached since long or short time.

The age of respondents is the only continuous covariate. It was centred on the rounded mean value of 33 years. As all of the other covariates are categorical, they were transformed into suitable dummy variables. Some collapsing of the categories was often needed: in such cases, several alternative collapsing schemes were tried in the model selection process. 
The educational level was measured with the following survey question: "How old were you when you stopped your full-time education?" and considered as a three-category variable with low (up to 15 years) medium (between 16 and 19) and high (20 years or above) level of education. A dummy variable indicating whether respondents were still enrolled in education at the time of the survey was also added.

The marital status was coded using four categories: single, married, cohabiting, and separated. The 'separated' category included also divorced and widowed people not living with another partner at the time of the survey, while the married category included remarried people.

The employment status has three categories: employed, unemployed and not active in the labour market.

A description of all the variables used in the models is reported in Table 2.

Table 2: Individual- and country-level variables used in the analysis. Values in per cent.

\begin{tabular}{lccc}
\hline & PARITY 0 & PARITY 1 & PARITY 2 \\
\hline & 20 & 48 & 84 \\
No child intended & 15 & 37 & 9 \\
One intended child & 48 & 13 & 6 \\
Two intended children & 16 & 2 & 1 \\
Three or more intended children & 29 & 34 & 37 \\
Age (average) & 55 & 38 & 39 \\
Male & 45 & 62 & 61 \\
Female & 20 & 21 & 21 \\
Climate change (strong) concerns & 80 & 79 & 79 \\
No climate change (strong) concerns & 19 & 64 & 75 \\
Married & 25 & 17 & 12 \\
Cohabiting & 54 & 10 & 5 \\
Single & 2 & 9 & 8 \\
Separated & 5 & 10 & 12 \\
Low education & 40 & 53 & 52 \\
Medium education & 35 & 36 & 35 \\
High education & 20 & 1 & 1 \\
Enrolled in education & & & \\
Employed & 64 & 74 & 76 \\
Unemployed or inactive & 36 & 26 & 24 \\
Low self-positioning on the social scale & 45 & 52 & 51 \\
High self-positioning on the social scale & 55 & 48 & 49 \\
\hline
\end{tabular}




\section{Results}

\subsection{Descriptive Analysis}

In the EU-27 as a whole, $20 \%$ of people of reproductive ages considered climate change the biggest problem of the future and 50\% reported it as one of the biggest problem. There is a cross-country variation in the share of people who are concerned, either weakly or strongly, that climate change will be a big problem in the future (Figure 2). The percentage goes from around 30\% in Luxembourg, Malta, Denmark, Germany east and Spain, to less than $10 \%$ in Portugal if we consider people who are strongly concerned. While it goes from more than 40\% in Greece, Cyprus, Germany East, Slovenia and Sweden, to less than 30\% in Malta, Lithuania, Latvia, Poland, Italy, Czech Republic and Portugal if we consider only those who are just weakly concerned about climate change (Figure 2).

Figure 2: Women and men of reproductive ages who consider climate change a problem for the future. 27-EU countries. Values in per cent.

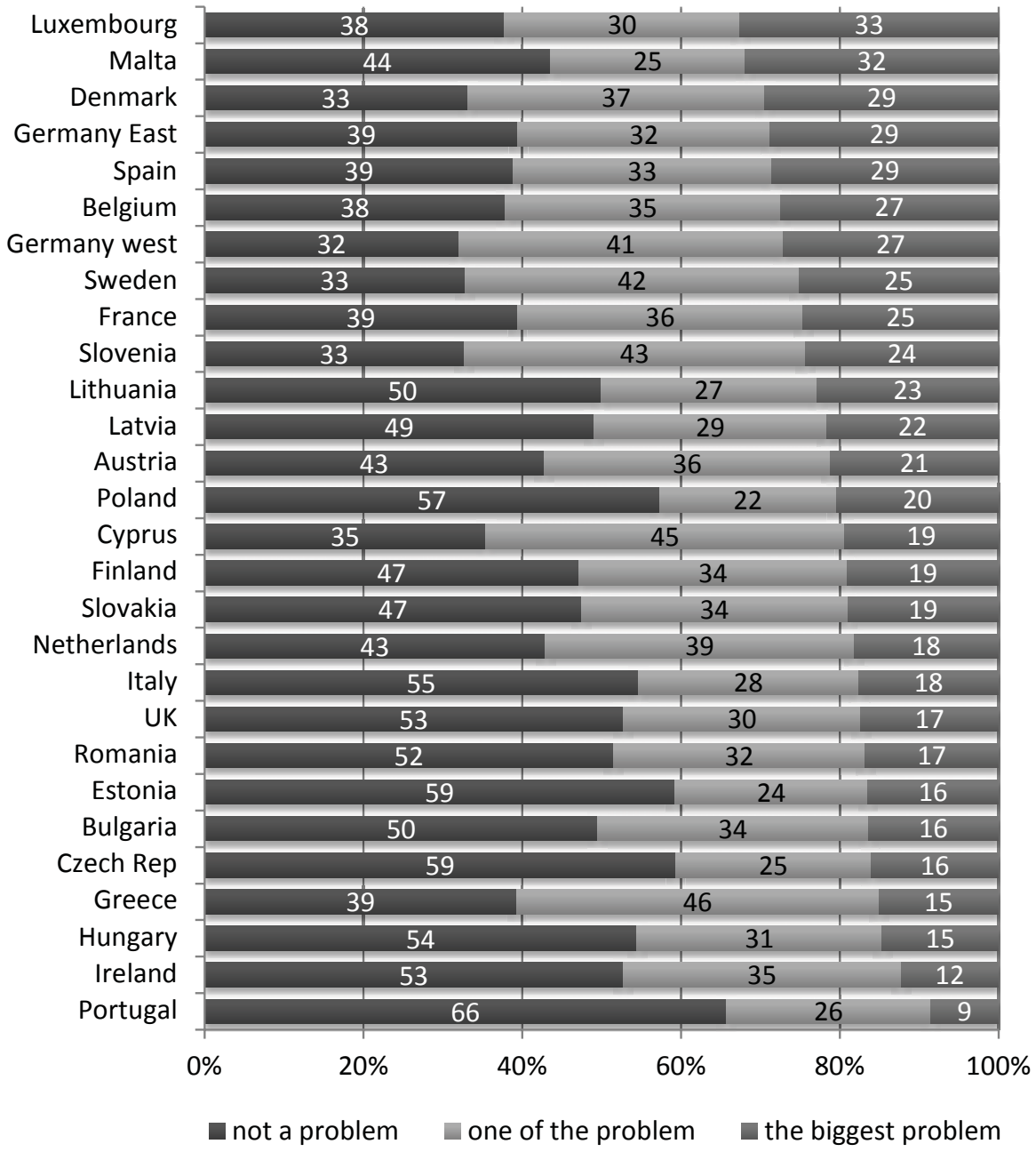


The mean ultimately intended family size, i.e., the sum of the mean actual and additionally intended number of children, is around two children in the EU-27 as a whole. There is a cross-country variation in both the mean actual and additionally intended family size: the mean actual family size goes from 0.8 in Italy to 1.6-1.7 in Latvia, France and Ireland. The mean additionally intended family size goes from 0.5-0.6 children in Portugal, Romania, Germany East and Luxembourg, to 1.1-1.2 children in Italy, Cyprus, and Ireland (Figure 3).

Figure 3: Mean ultimately intended family size decomposed in mean actual and mean additionally intended family size. Women of reproductive ages. 27 EU countries.

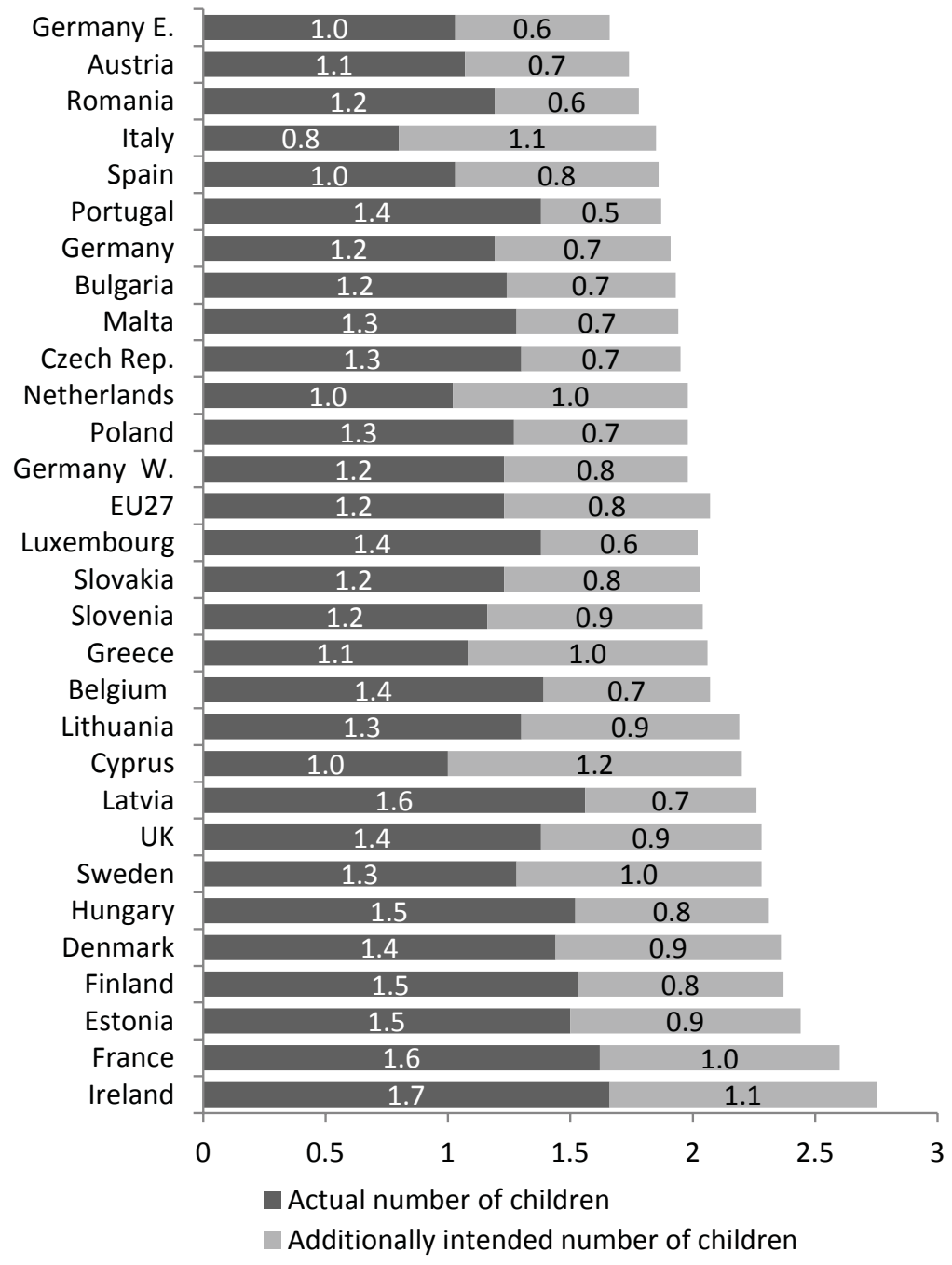




\subsection{Multilevel Models}

In Table 3 we report the estimates from the ordinal regression models on additionally intended number of children. In Table 6, the estimates of the ordinal regression models with a random intercept for the additionally intended number of children are reported. The models were run separately by parity zero, one, and two. Only the additionally intended children was considered in the response variable, to avoid problems of reverse causality which we would have faced by explaining events occurred already in the past (i.e., children already born) with characteristics measured only at the time of the survey (all the explanatory variables are measured at the time of the survey). Explanatory variables have been included gradually in the analysis: model I is the empty one, model II includes only the individual-level variables, and model III includes both the individual- and country-level variables.

As the table shows (Models II), at individual-level the additionally intended family size is negatively associated with age (for all the three parities), with the status of being inactive (only at parity zero), or single or separated (at parity one); by contrast, it is positively associated with a high level of education, enrolment in education, and a high self-positioning on the social scale (for all the three parities). Moreover, there is a positive and statistical significant gender effect in all of the models run which suggests that men plan to have larger family sizes than women (Table 3). Our key covariate, i.e., concern about climate change, has been included just as a dichotomous variable equal to one if people report to be strongly concerned about climate change, and zero otherwise. We did not keep in the models the additionally dummy indicating whether the people were just weakly concerned for reasons of models' parsimony, since the variable has never been statistically significant in the various specifications of the model.

As results of Table III show, people's concerns about climate change do not significantly influence individuals' additionally intended number of children. The relationship is, however, positive in models run on parity one and parity two and becomes slightly statistically significant in models for parity one. Unlike a negative relationship, as formulated in our initial hypotheses, the worries about the future because of climate change seem to be positively correlated with the intended family size, if any statistical significant correlation is detected at all. Moreover, this positive relationship does not change among the highly educated people, as suggested by the fact the interactions terms between climate change and high education have been never statistically significant, and hence, not retained in the final models reported in Table 3.

Eventually, the variance at the country-level is highly statistically significant, which justifies the adoption of a multilevel approach, but the country-level variable "concern about climate change" does not explain this variance in any of the models (Model I, II, and II) and the parities considered, as suggested by the fact that the country-level variance has not changed substantially after climate change variable has been included in the models at country-level. 


\section{Summary and Discussion}

In this analysis we investigated the relationship between people's concerns about climate change and fertility intentions in Europe (EU-27) by using the EB 2011 survey data and an integrated micro-macro model in which individuals are nested in countries. According to our initial research hypothesis, the relationship between climate change and fertility intentions is supposed to be negative, at individual and country level. Moreover, a differential impact by level of education is envisaged in our initial research questions according to which such a relation should be negative for the low to the medium educated people and positive for the highly educated ones. We could not support any of these results on the basis of the empirical evidence coming from the EB data: first, the relation between concerns about climate change and fertility intentions was found to be positive; second, there was not any relevant difference in this relation between the more and less educated people; third, there was not any statistically significant association detected at country level. These findings may not come as a surprise: indeed the reproductive decision-making process is rather complex (Morgan et al. 2011) and involve many factors, such as norms, attitudes and behavioural control (Ajzen 1991; Ajzen 2010), which we could not include in this study.

The results are not in line with those coming from the research conducted by Arnocky et al. (2012) in which the pollution related health concern was related to lower fertility intentions. The discrepancy may lie in the different data, approach and variables used. Arnocky and colleagues conducted their study in Canada and they used a variable measuring the impact of pollution on human beings' health conditions, while we just had a variable measuring the people's subjective perception of climate change as a major problem for the future.

Our data design has some limitations which may provide input for directions of future research on this topic. First, data are cross-sectional and thus they do not allow a dynamic study of the fertility decision-making process. Second, the limited national sample sizes prevent any detailed and reliable analysis at the national level, and moreover, the limited information available at individual level may cause the results to be biased due to omitted relevant variables. One relevant intervening variable in the relationship between climate change and fertility intentions could be the level of urbanization: sensitiveness to climate change problems may be expected to be higher in rural areas than in urbanized areas, since in the former ones there are more people who are employed in agricultural jobs, and hence, more directly exposed to some extreme weather conditions (flooding, droughts, etc.). In a previous version of the analysis we have included a variable measuring the urbanization level of the area in which people live, as subjectively measured by the respondents. This variable, however, did not turn to be relevant in the reproductive decision-making (intended number of children) nor in the impact of climate change on the reproductive decision-making (interaction effect between climate change and urbanization degree of the area). Third, the EB data do not allow a modelling of the selection effects generated by the postponement of childbearing.

Moreover, the causal direction is assumed to run from people's sensitivity to climate change to people's fertility intentions, although in actually there will be some degree of 
reverse causation, which we are not able to disentangle with the data at hand. In an earlier work based on the EB 2011 data (Testa and De Rose 2013) and in which the response variable in the models was the people's concerns about climate change, we found that ideal and the intended number of children were both positive and statistically significant correlated with the worries on climate change. This early finding coupled with those coming from the current analysis seem to suggest that people rather to see the choice of not having children (or having fewer children) as the most desirable one in an ecological perspective, start to think about the challenge related to the climate change when they have already planned or got children because they want to pass an healthy and enjoyable environment to their children's generation.

Eventually, 27 countries are not enough to produce very robust and reliable estimates at the country-level. Since the regional division of the EB data does not correspond to the NUTS 1 of the Eurostat, it was not possible to conduct the analysis at regional level while taking the regional-level variables from the statistics provided by Eurostat. It is hoped that it will be possible to address the issue in future studies on the basis of other data which do also measure the climate change threat more precisely. 


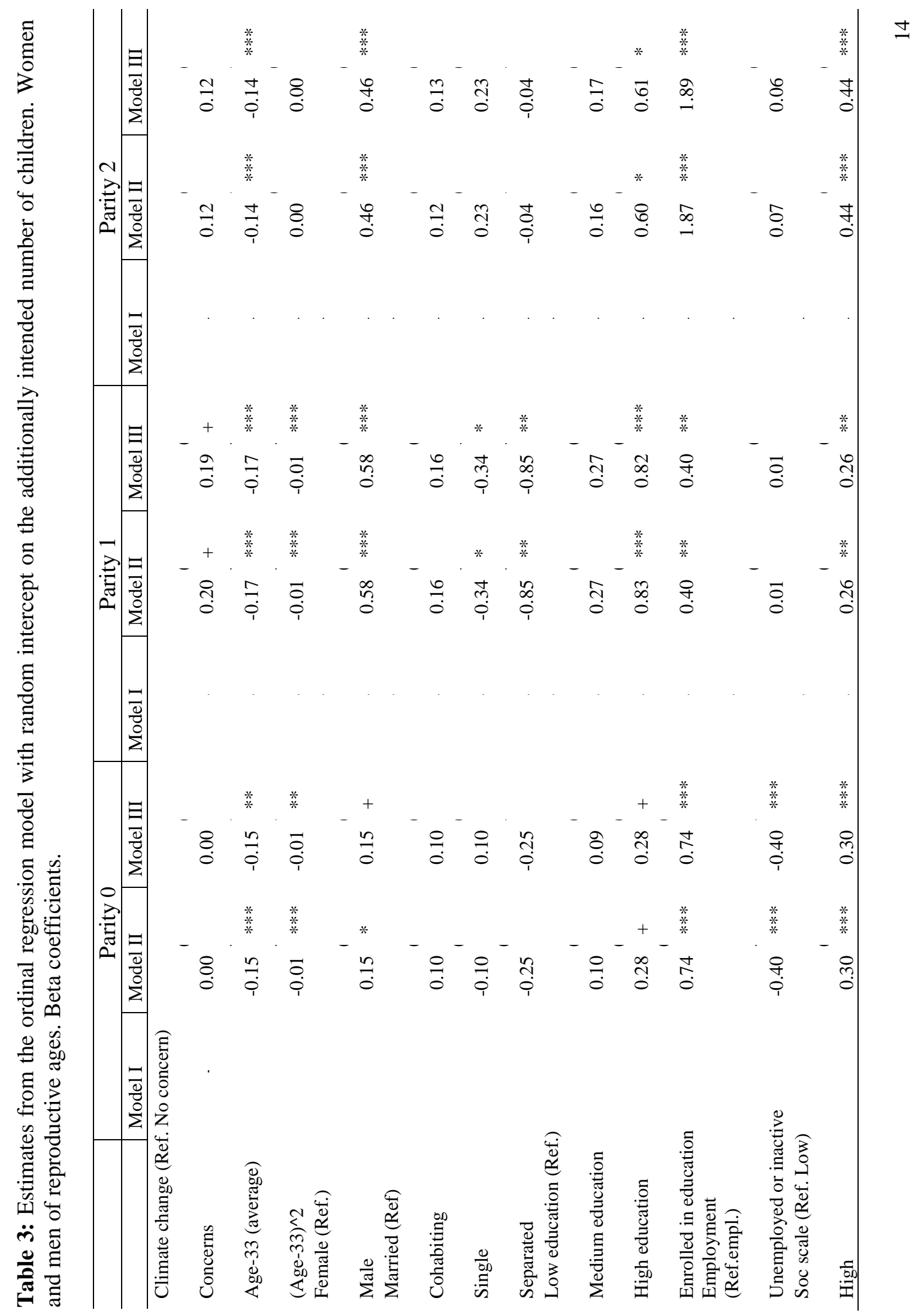




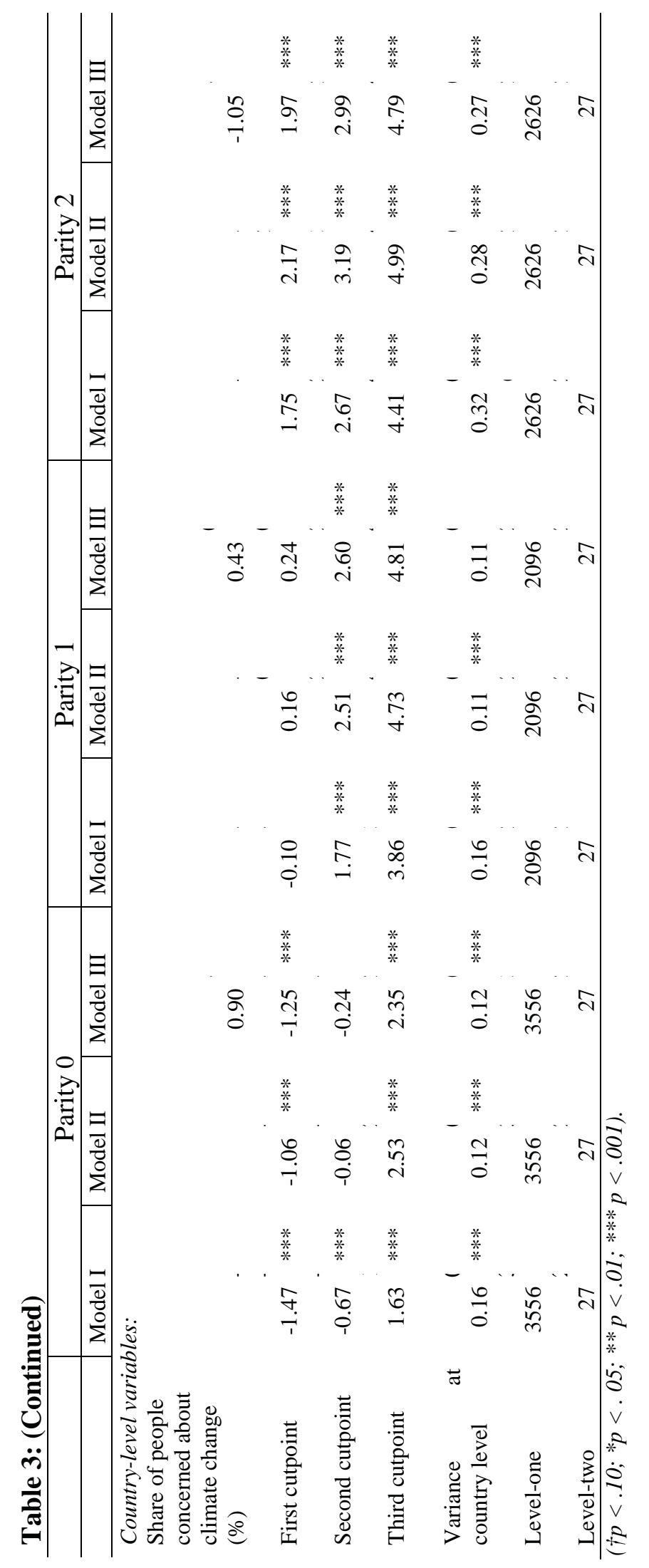




\section{References}

Agresti, A. 2002. Categorical Data Analysis. Second Edition, New York, Wiley.

Ajzen, I. 1991. The Theory of Planned Behavior. Organizational Behavior and Human Decision Processes, 50: 179-211.

Ajzen, I. 2010. Fertility intentions and the Theory of Planned Behaviour. Paper presented at the International Conference on Reproductive Decision-making in a Macro-Micro Perspective, Vienna, December 2-3, 2010.

Arnocky, S., Dupuis D., and M.L. Stroink. 2012. Environmental concern and fertility intentions among Canadian university students. Population and Environment 34:279-292.

Christensen, J.H., B. Hewitson, A. Busuioc, A. Chen, X. Gao, I. Held, R. Jones, R.K. Kolli, W.-T. Kwon, R. Laprise, V. Magaña Rueda, L. Mearns, C.G. Menéndez, J. Räisänen, A. Rinke, A. Sarr and P. Whetton. 2007. Regional Climate Projections. In: Climate Change 2007: The Physical Science Basis. Contribution of Working Group I to the Fourth Assessment Report of the Intergovernmental Panel on Climate Change [Solomon, S., D. Qin, M. Manning, Z. Chen, M. Marquis, K.B. Averyt, M. Tignor and H.L. Miller (eds.)]. Cambridge University Press, Cambridge, United Kingdom and New York, NY, USA.

Coleman, J.S. 1990. Foundations of social theory. Cambridge: The Belknap Press of Harvard University Press.

Confalonieri, U., B. Menne, R. Akhtar, K.L. Ebi, M. Hauengue, R.S. Kovats, B. Revich and A. Woodward. 2007. Human health. Climate Change 2007: Impacts, Adaptation and Vulnerability. Contribution of Working Group II to the Fourth Assessment Report of the Intergovernmental Panel on Climate Change, M.L. Parry, O.F. Canziani, J.P. Palutikof, P.J. van der Linden and C.E. Hanson, Eds., Cambridge University Press, Cambridge, UK, 391-431.

Costello A. et. al. 2009. Managing the health effects of climate change. Lancet, 373 (9694): 1693-1733.

Fritze, J.G., Blashki G.A., Burke S., Wiseman J. Hope 2008. Despair and transformation: climate change and the promotion of mental health and wellbeing. International Journal of Mental Health Systems, 2: 13.

Ghimire, D.J., and P. Mohai. 2006. Environmentalism and contraceptive use: How people in less developed settings approach environmental issues. Population and Environment 27(1): 29-61.

Hox, J., R. vand de Schoot, and S. Matthijsse 2012. How few countries will do? Comparative survey analysis from a Bayesian perspective Survey Research Methods 6,2: 87-93

Little, R.J.A. and D.B. Rubin. 2002. Statistical Analysis with Missing Data. II Edition, New York: Wiley.

Lutz W. 2010. What can demographers contribute to understanding the link between Population and Climate Change, POPNET, Population Network Newsletter n.41, IIASA 
Maranghi F. and Mantovani A. 2003. I contaminanti ambientali con effetti endocrini: problemi e prospettive. Notiziario dell'Istituto Superiore di Sanità. 16(5)

McBean G. and I. Ajibade. 2009. Climate change, related hazards and human settlements. Curr Opin Environ Sustain 1:179-186.

Morgan, S.P. 1981. Intention and uncertainty at later stages of childbearing: the United States 1965 and 1970. Demography 18(3): 267-285.

Morgan, S.P. 1982. Parity-specific fertility intentions and uncertainty: The United States 1970 to 1976. Demography 19(3): 315-334.

Morgan, S.P., Sobotka T. and M.R. Testa (Eds.) 2011. Vienna Yearbook of Population Research. Special issue on Reproductive decision-making. Vol.9. Vienna institute of Demography of the Austrian Academy of Sciences.

Namboodiri, K. 1972. Some observations on the economic framework for fertility analysis. Population Studies 26(2): 185-206.

O’Neill B.C. (ed.). 2002. Population in Sustainable Development. Analyses, Goals, Actions, Realities. Report of the Global Science Panel on Population \& Environment, an initiative of IIASA, IUSSP, and UNU. Available at www.iiasa.ac.at/gsp.

Piguet E. 2008. Climate change and forced migration. UNHCR Research Paper No. 153.

Rayner, S. and E.L. Malone (Eds) 1998. Human Choice and Climate Change: An International Assessment. Volume 1-4. Battelle Press, Columbus, Ohio.

Rendall, M. 2011. Breakup of New Orleans Households after Hurricane Katrina. Journal of Marriage and Family, 73, pp. 654-668

Skrondal, A. and Rabe-Hesketh, S. 2004. Generalized Latent Variable Modeling: Multilevel, Longitudinal and Structural Equation Models. Chapman and Hall/CRC.

Snijders, T.A.B. and R.J. Bosker. 1999. Multilevel Analysis. An Introduction to Basic and Advanced Multilevel Modeling. London: Sage Publications.

Stazi, A. and A. Mantovani 2001. Salute riproduttiva femminile e ambiente. Notiziario dell' Istituto Superiore di Sanità. 14(2)

Stegmueller, D. 2013: How many countries for multilevel modeling? A comparison of frequentist and Bayesian approaches” American Journal of Political Science 57, 3:748761.

Swim, J. Clayton S., Doherty T., Gifford R., Howard G., Reser J. et al. 2009. Psychology and global climate change: addressing a multifaceted phenomenon and set of challenges. Washington, DC: American Psychological Association.

Testa, M.R. 2012. Family size in Europe: evidence from the 2011 Eurobarometer survey. European Demographic Research Paper 1, Vienna Institute of Demography of the Austrian Academy of Sciences.

Testa, M.R., and A. De Rose. 2013. Cambiamento climatico e fecondità. Newsletter Neodemos. online 06/05/2013 http://www.neodemos.it

Williams, R. 2006. Generalized ordered logit/partial proportional odds models for ordinal dependent variables. The Stata Journal 61(1): 58-82. 
Yamaguchi, K. and L.R. Ferguson. 1995. The stopping and spacing of childbirths and their birth-history predictors: rational-choice theory and event-history analysis. American Sociological Review 60(2): 272-298. 


\section{VIENNA INSTITUTE OF DEMOGRAPHY}

\section{Working Papers}

Di Giulio, Paola, Thomas Fent, Dimiter Philipov, Jana Vobecká and Maria WinklerDworak, State of the Art: A Family-Related Foresight Approach, VID Working Paper 08/2013.

Sander, Nikola, Guy J. Abel and Fernando Riosmena, The Future of International Migration: Developing Expert-Based Assumptions for Global Population Projections, VID Working Paper 07/2013.

Caselli, Graziella, Sven Drefahl, Marc Luy and Christian Wegner-Siegmundt, Future Mortality in Low-Mortality Countries, VID Working Paper 06/2013.

Basten, Stuart, Tomáš Sobotka and Kryštof Zeman, Future Fertility in Low Fertility Countries, VID Working Paper 05/2013.

Sharygin, Ethan, The Carbon Cost of an Educated Future: A Consumer Lifestyle Approach, VID Working Paper 04/2013.

Winkler-Dworak, Maria and Heiner Kaden, The Longevity of Academicians: Evidence from the Saxonian Academy of Sciences and Humanities in Leipzig, VID Working Paper 03/2013.

Feichtinger, Gustav, Alexia Prskawetz, Andrea Seidl, Christa Simon and Stefan Wrzaczek, Do Egalitarian Societies Boost Fertility?, VID Working Paper 02/2013.

Muttarak, Raya, Is it (dis)Advantageous to Have Mixed Parentage? Exploring Education \& Work Characteristics of Children of Interethnic Unions in Britain?, VID Working Paper 01/2013.

Testa, Maria Rita and Stuart Basten, Have Lifetime Fertility Intentions Declined During the “Great Recession”?, VID Working Paper 09/2012.

Buber, Isabella, Ralina Panova, and Jürgen Dorbritz, Fertility Intentions of Highly Educated Men and Women and the Rush Hour of Life, VID Working Paper 08/2012.

Testa, Maria Rita, Laura Cavalli, and Alessandro Rosina, The Decision of Whether to Have a Child: Does Couple Disagreement Matter?, VID Working Paper 07/2012.

Kuhn, Michael and Klaus Prettner, Growth and Welfare Effects of Health Care in Knowledge Based Economies, VID Working Paper 06/2012.

Sander, Nikola and Martin Bell, Age, Period and Cohort Effects on Migration of the Baby Boomers in Australia, VID Working Paper 05/2012.

The Vienna Institute of Demography Working Paper Series receives only limited review. Views or opinions expressed herein are entirely those of the authors. 